\title{
Virtual teams versus face to face teams: A review of literature
}

\author{
Shikha Gera \\ (Faculty of Management Studies, University of Delhi, India)
}

\begin{abstract}
Today, concept of a team transcends the boundaries of distance, time, organizations and cultures. There has been an increasing emphasis on distributed work teams that operate in a virtual environment in a 24 hour cycle and tap the strength of diversity in terms of skills, experience, knowledge and expertise, all round the globe. Globalization and advances in Information and Communication Technology are a direct cause to it. The trend of distributed teams will not go way and will become the permanent work structures of the organizations. These global teams will profoundly reshape our world. But how effective are these teams compared to face to face teams? What are the differences between virtual teams and traditional teams? The paper extends knowledge on the growing importance of dispersed teams. The paper also builds on a comparison between virtual teams and face to face teams on the basis of certain dimensions such as group style, performance, satisfaction, trust, cohesion and conflict.
\end{abstract}

Keywords- Face to face teams, collocated teams, dispersed teams, traditional teams, virtual teams

\section{Introduction}

Progress in Information communication technology has produced new opportunities for organizations to develop new form of teams that are replacing traditional teams. It is due to the real time and flexible time communication that removes the communication barriers in dispersed teams. There are certain challenges such as lack of trust, cohesion and conflict that adds to the complexity in such teams. Previous researches have claimed the successful nature of virtual teams with respect to certain outcomes such as performance. Also, researchers have highlighted the existence of conflicts, lack of cohesion due to the diverse nature of the virtual teams. The purpose of the paper is to review previous researches on the growing importance of virtual teams and its comparison with face to face teams can gain a better understanding of ground realities of virtual and traditional environments so that we may effectively implement strategies to narrow the gap. The paper commences with the concept of a virtual team, definitions and its benefits and proceeds to the comparison of traditional and dispersed teams on the basis of group styles, performance, satisfaction, trust, cohesion and conflicts.

\section{VIRTUAL TEAM}

Teams have been one of the most fascinating organizational types in the preceding decades [1, p.5] and refers to a "small task group in which the members have common purpose, interdependent roles and complementary skills" [2, p.337] that are used in various applications such as problem solving, product development, decision making, planning, negotiation etc. [3]. Advances in information and communication technology have enabled a faster pace of change in organizational structures, systems and processes. Thus, there has been an increasing emphasis on far flung, distributed "virtual" teams as organizing units of work [4]. Virtual teams can be defined as: "Teams whose members use technology to varying degrees in working across locational, temporal and relational boundaries to accomplish an interdependent task" [5, p.808]. Townsend et al. [1] defined virtual teams as "Groups of geographically and/or organizationally dispersed co-workers that are assembled using a combination of telecommunications and information technologies to accomplish an organizational task" (p.17). According to Suzzane [6] "A virtual team is a group of dispersed workers with distinct skills who focus on a specific goal on a temporary or ongoing basis" (p.45).

"Virtual teams are networks effective, value based, swiftly reconfiguring, high performance, costsensitive and decentralized and will profoundly reshape our world [7, p.19]. One of the benefits of the virtual team environment is its ability to efficiently and effectively connect people, extends resources [1] and enables greater levels of productivity $[1,6,8]$. Virtual teams operate in a twenty four hour cycle and tap the strength of diversity in terms of skills, experiences and knowledge about customers and business [9,10] save money [6] allows creativity and innovativeness $[8,11]$ and originality among team members, promote equality among employees and discourage race discrimination [11]. Morale development, cost reduction, shorter cycle times, a larger talent pool and work life balance are the by-products of virtual teams [8]. The culturally dispersed teams lead to innovative solutions as well [12].

In a virtual team, information sharing is done through the internet, e-mail and teleconferencing. The technology is the means by which members relate and communicate with each other. All members have access 
to the same information through these facilities [13]. Online communication and collaboration are supported by a variety of computer mediated communication systems (CMCS). In general two broad categories of systems exist [14]. Synchronous technology supports same time interaction such as audio-video conferencing and web chat rooms. Asynchronous technology allows different time interaction like e-mail and web based bulletin boards [15]. The members in a virtual team communicate better using e-mail, text chat or threaded discussions because the focus is on the written word [14].

\section{Virtual Teams Versus Face To Face Teams}

Bell et al. [4] maintained that traditional teams work in close physical proximity and work under the same roof having face to face interactions while virtual teams, on the other hand are physically separated and rely on host of technologies such as electronic mail, videoconferencing, electronic-mails, telephones and groupware (hardware and software applications that facilitate group work) for communication and information exchange. Virtual teams are more complex in comparison to face to face teams as (a) they cross boundaries related to time, distance (geography) and organization and (b) they use electronic technological means to communicate and collaborate i.e. they are compared on the basis of spatial distance and communication media $[4,12]$.

Geographically dispersed communication does not contain close physical proximity, frequency of interaction, and breadth and depth of physical cues through non-verbal communication as compared to face to face teams [16]. According to Mahhailova [17] virtual teams are characterised by demerits like slow feedback, lack emotions, lack visual and audio contact. The team task is so highly structured that coordination by team members is very difficult in virtual teams in comparison to face to face teams [18]. Andres [19] predicted in a laboratory experiment that the face to face groups did experience greater perceived interaction quality because of the opportunity to utilize increased verbal, non-verbal and back channelizing cues to promote efficient turntaking, immediate feedback and confirmation of conceptual consensus as compared to the videoconferencing supported groups. Virtual teams face more complexity, invisibility and restricted communication than face to face teams due to the nature of tasks, culture, language and diversity [20]. Kayworth and Leidner [21] argued that team members interpret communicated information through inherent cultural biases that may lead to miscommunications, misinterpretations or distortions $[8,21]$. As cultures differ, sharing of knowledge may also get affected [22]. The following section deals with the empirical researches that focus on the comparisons between face to face and virtual teams on the basis of styles, performance, satisfaction, trust, cohesion and conflicts.

\subsection{Styles}

The study by Branson, Clausen and Sung [23] found that face to face teams function differently than computer mediated communication teams on the basis of styles. In a sample of sixty two teams at a Midwestern University, 30 teams were face to face and 32 were virtual teams. They found that face to face teams scored higher on self-actualizing style thereby welcomed creative and innovative solutions. Face to face teams also, scored higher on humanistic encouraging style, wherein members supported and assisted each other constructively. They also scored higher on affiliative style, wherein members were strongly committed to the group i.e. face to face teams were more prone to constructive group style. On the other hand virtual teams were more prone to passive/defensive-dependent, avoidance or aggressive/defensive- power oriented dimensions that led to inferior decisions. Hambley, O'Neill, and Kline [24] in a sample of 228 students from Canadian University comprising of 60 experimental teams with 3-4 participants in each team found that the mean constructive interaction score was higher in face to face teams than videoconference and chat teams.

\subsection{Performance}

An experimental study by Staples and Jhao [25] in seventy nine teams examined the effect of cultural diversity on team effectiveness working face to face or virtually. The researchers found the performance of the virtual heterogeneous teams was superior to that of face to face heterogeneous teams. Purvanova and Bono [26] found that transformational leaders' behaviours were positively linked to performance in virtual teams than face to face teams. Hambley et al. [24] found that higher task performance was achieved in rich media than those communicating through less rich media.

\subsection{Satisfaction}

Staples et al. [25] found that virtual teams were generally less satisfied due to heterogeneous nature of the teams. Cicei [27] examined the satisfaction level of 80 students enrolled in a master program who learned and worked in both online (40 students) and offline settings (40 students). A total of ten teams were assigned a practical academic project. Members in face to face teams were more satisfied with the quality of team working than virtual teams. For work-process satisfaction face to face teams were more satisfied than virtual teams. No 
significant differences were obtained between the two types of teams with respect to work output satisfaction. Both the teams were moderately satisfied by the outputs of their work.

\subsection{Trust}

Hill, Bartol, Tesluk and Langa [28] in a sample of 208 participants i.e. 104 manager dyads found that relative to introductory meeting communication medium (face to face vs electronic), context (cooperative vs competitive) exerts a more powerful influence on trust and collaborative behaviours between computer mediated work partners. They also found that a cooperative context facilitated high levels of trust and collaborative behaviours regardless of the medium used for the introductory meeting. In a competitive context, a face to face introductory meeting plays a larger role in facilitating the development of trust and collaborative behaviours.

\subsection{Cohesion}

Warkentin, Sayeed and Hightower [29] compared 13 teams using an asynchronous technologies with 11 traditional face to face teams and found that face to face groups had stronger relational links, reported a higher degree of cohesion, were more satisfied with the team's outcome and decision process than computer mediated communication systems (CMCS) groups. Hambley et al. [24] found that mean team cohesion scores were higher in FTF and videoconference than chat teams, but not significantly higher in FTF than videoconference teams. Staples et al. [25] explored less cohesion in virtual teams.

\subsection{Conflict}

Virtual teams due to its dispersed and diverse nature tend to experience greater and more diverse conflict compared to co-located teams [10]. Staples et al. [25] explored more conflicts in virtual teams. Liu, Luo and Wei [30] in their experimental research on 20 teams of four members each in face to face and virtual teams (i.e 160 subjects) from U.S. and China, found that more conflict prevailed in virtual teams than face to face teams due to diverse nature of teams and lead to different conflict management behaviours in global virtual teams such as collaboration, competition and avoidance. A study by Mortensen and Hinds [31] in a sample of 24 teams product development distributed and collated teams from five companies found that there was more task conflict on teams that relied heavily on technology to mediate their communication, and conflict was more detrimental to virtual than face to face teams.

\section{Conclusion}

Virtual teams provides with a structure that makes it possible for individuals to work for an organization across time and space. Researchers have found that members of face to face teams are more satisfied, supportive and provide innovative solutions due to self actualizing and constructive style. Members of the virtual teams on the other hand are more prone to conflicts, less satisfied and have inferior decision making due to passive and aggressive style. There are no significant differences found on the basis of performance. Also, trust and cohesion can be developed overtime and is generally found more in teams that use richer media in comparison to less rich media. Successful virtual organizations are those wherein collaboration, cohesion and trust takes place among individuals. Despite the challenges faced, companies are investing heavily on organizations to recruit the talents and expertise. Training can help to overcome these challenges.

\section{References}

[1] A.M. Townsend, S.M. Demarie, and A.R. Hendrickson, Virtual Teams: Technology and the workplace of the future, Academy of Management Executive, 12(3), 1998, 17-29.

[2] G.A. Yukl, Leadership in Organizations (India: Prentice Hall, 2006).

[3] E. Sundstrom, K.P. De Meuse, and D. Futrell, Work teams: Applications and effectiveness, American Psychologist, 45(2), 1990, 120-133.

[4] B.S. Bell, and S.W. Kozlowski, A typology of virtual teams: Implications for effective leadership, Group and Organization Management, 27(1), 2002, 14-49.

[5] L.L. Martins, L.L. Gilson, and T.M. Maynard, Virtual teams: What do we know and where do we go from here? Journal of Management, 30(6), 2004, 805-835.

[6] G. Suzanne, Virtual teams, real benefits, Network World, 18(39), 2001, 45.

[7] J. Lipnack, and J. Stamps, Virtual teams: The new way to work, Strategy and Leadership, 27(1), 1999, 14-19.

[8] E.L. Mourino-Ruiz, Effective leader-employee relationships in the 21st century, in E. Beich (Ed.), The 2010 pfeiffer annual consulting (San Francisco: John Wiley and Sons, 2010) 265-280.

[9] J. Lipnack, and J. Stamps, Leading virtual teams: Expert solutions to everyday challenges (Boston: Harvard Business Press, 2010).

[10] R.L. Wakefield, D.E. Leidner, and G. Garrison, Research Note- A model of conflict, leadership and performance in virtual teams, Information Systems Research, 19(4), 2008, 434-455.

[11] B.J. Bergiel, E.B. Bergiel, and P.W. Balsmeier, The reality of virtual teams, Competition Forum , 4(2), $2006,427-432$.

[12] D.L. Duarte, and N.T. Snyder, Mastering virtual teams: Strategies, tools and techniques that succeed (San Francisco: Jossey Bass, 2006).

[13] K. Singh, (Organizational Behaviour: Text and Cases. (India: Pearson Education, 2010).

[14] C.J. Friday, Global virtual teams: Challenges of technology and culture, in E. Biech (Ed.), The 2008 pfeiffer annual consulting (San Francisco: John Wiley and Sons, 2008) 205-213. 
[15] L. Bradley, The technology that supports virtual team collaboration, in J. Nemiro, M. Beyerlein, L. Bradley, \& S. Beyerlein (Eds.), The handbook of high performance virtual teams: A toolkit for collaborating across boundaries (San Francisco: Jossey Bass, 2008) 331-343.

[16] R.K. Hart, Constituting relationships in communication: An interdisciplinary approach to understanding peer relationships in geographically dispersed teams, in M. M. Beyerlein, D. A. Johnson, \& S. T. Beyerlein (Eds.), Advances in interdisciplinary studies of work teams: Virtual teams (Amsterdam: Elsevier Science Ltd, 2001) 85-106.

[17] G. Mihhailova, Virtual teams - just a theoretical concept or a widely used practice?, The Business Review, 7(1), 2007, 186-192.

[18] N.A. Ebrahim, S. Ahmed, and Z. Taha, Virtual teams: A literature review, Australian Journal of Basic and Applied Sciences, 3(3), 2009, 2653-2669.

[19] H.P. Andres, A comparison of face-to-face and virtual software development teams, Team Performance Management, 8(1/2), 2002, 39-48.

[20] A. Baan, and M. Maznevski, Training for virtual collaboration: Beyond technology competencies, in J. Nemiro, M. Beyerlein, L. Bradley, and S. Beyerlein (Eds.), The handbook of high performance virtual teams: A toolkit for collaborating across boundaries (San Francisco: Jossey Bass, 2008) 345-365.

[21] T.R. Kayworth, and D.E. Leidner, Leadership effectiveness in global virtual teams, Journal of Management Information Systems, 18(3), 2002, 7-40.

[22] N. Zakaria, A. Amelinckx, and D. Wilemon, Working together apart? Building a knowledge sharing culture for global virtual teams, Creativity and Innovation Management, 13(1), 2004, 15-29.

[23] L. Branson, T.S. Clausen, and C. Sung, ( Group style differences between virtual and F2F teams, American Journal of Business , 23(1), 2008, 65-70.

[24] L.A. Hambley, T.A. O'Neill, and T. Kline, Virtual team leadership: The effects of leadership styles and communication medium on team interaction styles and outcomes, Organizational Behavior and Human Decision Processes , 10(1), $2007,1-20$.

[25] D.S. Staples, and L. Jhao, The effects of cultural diversity in virtual teams versus face to face teams, Group Decision and Negotiation, 15, 2006, 389-406.

[26] R.K. Purvanova and J.E. Bono, Transformational leadership in context: Face-to-face and virtual teams, The Leadership Quarterly, 20, 2009, 343-357.

[27] C.C. Cicei, Assessing members' satisfaction in virtual and face to face teams, Procedia-Social and Behavioral Sciences , 46, 2012, 4466-4470.

[28] N.S. Hill, K.M. Bartol, P.E.Tesluk, and G.A. Langa, Organizational context and face to face interaction: Influences on the development of trust and collaboration behaviors in computer mediated groups, Organizational Behavior and Human Decision Processes, 108(2), 2009, 187-201.

[29] M.E. Warkentin, L. Sayeed, and R. Hightower, Virtual teams versus face to face teams: An exploratory study of a Web-based conference system, Decision Sciences , 28(4), 1997, 975-996.

[30] Y. Liu, M. Luo, and X. Wei, The effects of cultural diversity, conflict and conflict management on performance in global virtual teams., Proc. $4^{\text {th }}$ IEEE International Conf. on Wireless Communications, Networking and Mobile Computing, Dalian, China, 2008, $1-4$.

[31] M. Mortensen, and P.J. Hinds, Conflict and shared identity in geographically distributed teams, The International Journal of Conflict Management, 12(3), 2001, 212-238. 